\title{
Research on the Problems and Countermeasures of Chinese Teachers in Vocational Education Training
}

\author{
Changzhao Guo \\ Handan Polytechnic College \\ Handan, China \\ Guochangzhao1217@163.com
}

\begin{abstract}
Vocational education is an important part of higher education and the teacher plays a significant role in vocational education. However there are still some problems in it. So we should further expand the content and form of teacher training to solve the problems. Some measures should be taken to assess the effect such as to strengthen the assessment monitoring the training process, to enhance the training outcomes assessment and so on to increase the training effect, to promote the improvement of the overall quality of teachers. This article through the main problems of teacher training in higher vocational colleges and put forward the corresponding solution strategies to improve the quality of teachers, thus contributing to the common development of vocational colleges and teachers to achieve lifelong education of teachers.
\end{abstract}

Keywords-Vocational Colleges; Teacher Training; Lifelong Education

\section{INTRODUCTION}

With the deepening of vocational education to flourish and reform, teachers vocational colleges are facing severe challenges, and improve the overall quality of teachers has become a key issue. To develop the higher vocational education, we must have a high comprehensive quality and reasonable structure that adapt to the development of higher vocational education teachers. Faculty building is the most basic teaching construction and is the fundamental guarantee of improve the quality of higher vocational education, is the basis of the development of social economy and accelerate economic construction. Have a high overall quality of the team in order to cultivate high-quality talent, and reflects the academic status of vocational colleges and overall strength. The training is to improve the overall quality of teachers colleges, an important way to promote the professional development of teachers in vocational colleges. Vocational teacher training colleges are the most effective way to improve the overall quality of teaching vocational colleges. The key lies to ensure the quality of education and vocational colleges to promote its healthy and rapid development in teacher training, so that establish a highly qualified faculty and achieve lifelong development of teachers.

\section{THE IMPORTANCE OF VOCATIONAL TEACHER TRAINING}

\section{A. The Need of Optimizing the Management of Human Resources}

The essence of human resources management is to take effective way for talent of education, training, etc., to explore their inner quality and create volume potential to improve the quality of its personnel and application skills better. With the development of the network, information technology and other information technology, quality educational resources coplanar expand students' self-learning ability and constantly improve their quality. Their means of acquiring knowledge and career will have teachers demanded higher, which also require college teachers must have higher quality, thus the training of teachers, is to enhance their professional skills, and improve the overall quality of the teachers need, and should ensure that teacher training normalization[1].

\section{B. The Need of Training "Double Teachers"}

"Double Teachers" is a trend in the world, both as teachers are required to have professional theoretical level, but also requires teachers to have professional practice skills. Currently teachers in vocational colleges or in the main undergraduate, they have a strong foundation of professional knowledge, but a lack of practice and training industry, which requires that they must carry out in-depth business practice through teacher training, research and innovation, and social services master the ability to better qualify teaching needs, to better serve the economic and social development [1].

\section{The Need of Vocational Education "School Characteristics"}

With the gradual development of technology, productivity revolutionary changes taking place in the industrial structure and labor structure will happen with these profound changes. "Knowledge economy" and "new road to industrialization" skills of workers called for further improvement and this is where the fundamental difference between higher education "academic" type of personnel training and vocational education "skills" type talents. Over the years, college teachers are from professional colleges, the general lack of industry practice both frontline exercise, which requires us to develop practical skills of teachers through teacher training, which reflects the "school characteristics" Higher Vocational Education[1]. 


\section{The Problems Of Vocational TeAcher Training}

\section{A.The Single Training Content and Form}

Teaching staff from regional countries, the in-service training and training under considerable attention, however, a single form of training, targeted training content, practicality is not strong. Many teachers professional training is basically in the form of lectures, lack of teacher participation and interaction. Some training involves broad, not addressed to a particular professional field or specialized skills, learning without teacher's application, and training are mostly around theoretical study, the lack of or no practical aspects, leading to teachers' professional skills training is not enough.

\section{B. The Unsound Training System}

School teaching department, academic departments, insufficient coordination between the personnel department not in close coordination smooth enough so that there is a disconnect teacher training phenomenon, some training programs do not meet the teaching and training work, resulting in financial and human waste[4]. In addition, industries and enterprises for sending work with teacher training is not enough.

Due to the production and operation of enterprises, the pursuit of profit maximization for the purpose of business is not willing to receive teacher testing exercise, or for attachment to the guidance of teachers and management in place, the teacher testing exercise ineffective.

\section{The Evaluated Effectiveness of Training Formality}

After the training, whether to achieve the desired objectives, participate in the training of teachers is the application of knowledge and skills learned for the hospital to create a proper value, which must be carried out to assess the effectiveness of training. However, the current vocational colleges just to organize training, but rarely be evaluated, so that over a period of time after training, there is little attention to the teacher how to change behavior at work, rarely Academy training results summary induction, making it difficult to provide an effective basis for the next step of the training program needs[3].

\section{The Limited Training Funding}

Most vocational colleges are transformed from ordinary colleges or adult institutions set up independently from, in its, the cost for the stage by the administration in charge of colleges. After the restructuring of colleges, administrations only pay for part of the investment in construction, the remaining funds raised by the school to solve the shortfall. The current school funding vocational colleges is generally tight, many vocational colleges unable to provide adequate funding for teachers to learn. Training funds shortage has been a major factor restricting vocational teacher training colleges.

\section{The Measures Of Vocational Teacher TRAINING ISSUES}

\section{A. To Broaden the Content and Form of Teacher Training}

According to the characteristics of higher vocational education, teacher training can be divided into the following forms: the school curriculum in schools through training to teachers, interactive and outside experts to give lectures in schools as the main form, through teaching and research activities for all teachers in a full training. Job training, business training can be short-term studies; can be accessed at home and abroad to learn the identity of academics, research skills can be trained, but also to similar institutions to visit, study and exchange of good practices and experiences. Enterprise attachment, that "Double" focus on strengthening vocational college teachers team building, vocational colleges to increase teacher training efforts; in addition, you should create a variety of training channels, improve the training system. Specific measures for the creation of: Building structured training system of knowledge; build a reasonable implementation of the training system, the establishment of a harmonized system of training organizations. And teacher training needs to guide the national level, the active participation of local government support and vocational colleges [4].

\section{B. To Strengthen the Industry's Enterprises with Teacher Training}

To support training for industry and all sectors of society, take full advantage of all aspects of the industry, business and social resources, including equipment, facilities, personnel, and funding, to leverage existing training base; Rely on institutions of higher learning and career school research department and enterprise groups, expertise, learning new theories of international and other provinces and vocational education. Achieve the participation of the government, industry associations and schools in the organization, do their duties and enhance teachers' ability to form a comprehensive top-down, bottom-up work situation.

\section{To Establish a Reasonable Assessment and Evaluation Mechanisms}

Assessment and evaluation is an important part of the overall management system, which is to ensure that the basis and premise of competition and incentives works effectively. After the training, the full implementation of the qualitative assessment, the target to the people, to ensure that every teacher training can grasp the central idea of the training, so that in the future education of life will have learned to use the content classroom. In the evaluation process, not just focus on the results of the assessment, the assessment process is ignored, it should take the test and practice, in quantity and qualitative, the study focused on the teaching of teachers, research and innovation, and social service capabilities. And in order to promote continuous learning and teachers' continuous professional development, the school can specify the appropriate performance appraisal system, out of the outstanding teachers and outstanding engineers founded industry capacity assessment team to ensure a reasonable assessment sister decisive and fair [2]. 


\section{To Increase Funding for Teacher Training}

Due to restrictions, vocational colleges do not have enough funds research work conditions. In order to improve the level of service quality of existing teachers, the faculty should create an appropriate experimental schools, training base, in order to provide teachers with more practical internship sites, improving teachers' awareness division of research and research capacity, accelerate update teaching content and teaching. Moreover, schools should actively create conditions and provide certain funds, selected teachers to colleges and universities, training centers or training bases at home and abroad to attend the training. National and local educational administrative departments need to further strengthen support for teacher training, strengthen coordination within the area of teacher training, to provide the necessary financial support. The Government approved the establishment of teacher colleges and vocational training should be given preferential policies and financial support. Its limited funding colleges should have a reasonable teacher with teacher training to increase funding to ensure the development of a training program to be implemented [5].

\section{CONCLUSIONS}

In short, teacher training is a faculty building an important part of vocational colleges to strengthen the research faculty building colleges, so that the construction of vocational teachers in the economic, technical, scientific research and international and domestic advanced productive forces combination, to be able to promote the healthy development of vocational education. Vocational colleges should fully recognize the importance of teacher training, and actively create conditions to support and help teachers to actively participate in social practice and other training to improve the quality of existing teachers, meanwhile, also for the issue of teacher training, taking changes in consciousness scientific development of teacher training programs, the creation of a variety of training, channels improve the training system to ensure funding for teacher training, strengthen teacher training needs analysis and training to improve the relevance and validity of a series of measures to improve teacher training, and ultimately vocational colleges and common development of teachers, lifelong development and achieve win-win situation.

\section{ACKNOWLEDGMENT}

Heartfelt thanks to the "second profession Education Reform and Modern Management International Conference," for giving me this opportunity to learn. The research level of mine has been further improved. Although the article was finished, the exploration knowledge of the road is still long. Through research study, led me have more profound understanding about "learn and know enough," will enable me to continue to explore in future work.

\section{REFERENCES}

[1] Yan Yan, "Investigate the problem of teacher training vocational colleges,” [J] Yunyang Teachers College, 2013,03: 113-115.

[2] Feng Zhao, "Break through the bottleneck of vocational teachers to enhance the teaching ability,”[N]. China Education Daily, 2008-08-08008.

[3] Yanzi Xiang, "Vocational colleges to swallow study teacher training issues,” [J] Changsha Railway University (Social Sciences), 2007,04: 216-217.

[4] Liuping Lu, "Vocational teacher training colleges Problems and countermeasures,” [J] Guangxi Education, 2011,03: 114 + 117.

[5] Youqin An, "Vocational Education Teacher Training Problems and countermeasures," [J] Science and Technology Innovation Herald, 2012,35: 2 . 